\title{
A following car influences cyclist drag: CFD simulations and wind tunnel measurements
}

\author{
Bert Blocken $^{\mathrm{a}, \mathrm{b}} *$, Yasin Toparlar ${ }^{\mathrm{a}}$ \\ ${ }^{a}$ Department of the Built Environment, Eindhoven University of Technology, P.O. Box 513, 5600 Eindhoven, \\ The Netherlands \\ ${ }^{b}$ Department of Civil Engineering, Leuven University, Kasteelpark Arenberg 40 - Bus 2447, 3001 Leuven, \\ Belgium
}

\section{Graphical abstract}

\section{Following car reduces cyclist drag}

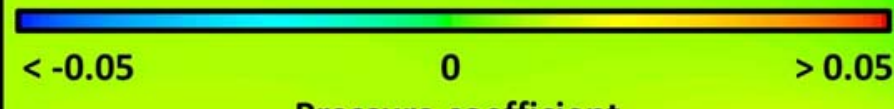

Pressure coefficient
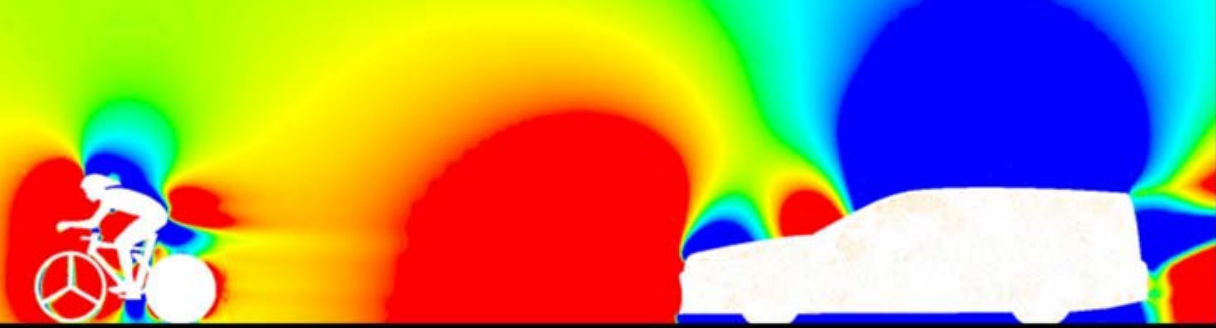

Highlights:

- Downstream effect of car on cyclist riding behind it is well-known.

- This paper studies upstream effect by a following car riding behind a cyclist on cyclist drag.

- The International Cycling Union (UCI) sets a minimum distance of $10 \mathrm{~m}$ for safety reasons.

- For $10 \mathrm{~m}$ distance, CFD simulations and wind tunnel tests show a $3.9 \mathrm{~s}$ impact on a $50 \mathrm{~km}$ time trial.

- The UCI should shift its $10 \mathrm{~m}$ limit to $30 \mathrm{~m}$ to avoid this undesired aerodynamic effect.

\footnotetext{
* Corresponding author: Bert Blocken, Building Physics and Services, Eindhoven University of Technology, P.O.Box 513, 5600 MB Eindhoven, the Netherlands. Tel.: +31 (0)40 247 2138, Fax +31 (0)40 2438595 E-mail address: b.j.e.blocken@tue.nl
} 


\title{
A following car influences cyclist drag: CFD simulations and wind tunnel measurements
}

\author{
Bert Blocken $^{\mathrm{a}, \mathrm{b}} *$, Yasin Toparlar ${ }^{\mathrm{a}}$ \\ ${ }^{a}$ Department of the Built Environment, Eindhoven University of Technology, P.O. Box 513, 5600 Eindhoven, \\ The Netherlands \\ ${ }^{b}$ Department of Civil Engineering, Leuven University, Kasteelpark Arenberg 40 - Bus 2447, 3001 Leuven, \\ Belgium
}

\begin{abstract}
It is well-known in elite cycling that a cyclist riding behind a car experiences a substantial reduction in aerodynamic resistance or drag. However, the upstream effect by a following car on the cyclist in front of it is not well-known and has, to the best of our knowledge, not yet been reported in the scientific literature. It is also not taken into account in elite cycling, as for individual time trials, the rules of the International Cycling Union (UCI) only specify a minimum distance between rider and car of $10 \mathrm{~m}$ because of safety reasons. Furthermore, during actual races, this limit is often not kept and not strictly enforced. Nevertheless, during individual time trials, there is always at least one, but often more, following cars, potentially influencing the cyclist drag. This study presents the results of CFD simulations and wind tunnel measurements to ascertain and quantify the upstream effect by a following car on the drag of the cyclist in front of it. CFD simulations are performed based on the steady-state Reynolds-Averaged Navier-Stokes equations with the standard k- $\varepsilon$ model for closure. The simulations are validated based on a series of wind tunnel measurements. The drag reduction for the cyclist ranges from $3.7 \%$ over $1.4 \%$ to $0.2 \%$ for realistic separation distances of 3,5 and $10 \mathrm{~m}$, respectively. For a typical $50 \mathrm{~km}$ individual time trial, the potential time reduction by exploiting this effect (e.g. by a car following the rider at this short distance versus no car behind) is $62.4 \mathrm{~s}, 24.1 \mathrm{~s}$ and $3.9 \mathrm{~s}$, respectively. As elite cyclist time trials are often won based on seconds or sometimes even less, these differences can be decisive for who wins the stage. Therefore, it is recommended that the UCI not only raises its current minimum separation distance of $10 \mathrm{~m}$ to at least $30 \mathrm{~m}$, but also strictly enforces it, to avoid this unwanted aerodynamic effect that can influence the outcome of the race.
\end{abstract}

Keywords: Computational Fluid Dynamics; wind tunnel; aerodynamic cyclist drag; cycling aerodynamics; following car; numerical simulation

\section{Introduction}

"The greatest potential for improvement in cycling speed is aerodynamic" (Wilson 2004). At racing speeds (about $54 \mathrm{~km} / \mathrm{h}$ or $15 \mathrm{~m} / \mathrm{s}$ in time trails), the aerodynamic resistance or drag is about $90 \%$ of the total resistance (Kyle and Burke 1984; Grappe et al. 1997; Lukes et al. 2005). Aerodynamic drag can be investigated by field tests, wind tunnel measurements and numerical simulation by Computational Fluid Dynamics (CFD).

The use of CFD in wind engineering, also referred to as Computational Wind Engineering, has seen a rapid growth in the past 50 years (Blocken 2014). This growth has been strongly supported by the development of best practice guidelines for CFD (Casey and Wintergerste 2000, Franke et al. 2007, Britter and Schatzmann 2007, Tominaga et al. 2008, Blocken 2015) and review, overview and position papers (e.g. Stathopoulos 1997, 2002, Murakami 1997, Murakami et al. 1999, Meroney 2004, Blocken and Carmeliet 2004, Mochida and Lun 2008, Tominaga and Stathopoulos 2013, Blocken 2014, 2015). Indeed, also in cycling aerodynamics, several publications have reported CFD simulations (Hanna 2002, Lukes et al. 2004, Defraeye et al. 2010a, 2010b, 2011, 2014, Blocken et al. 2013).

\footnotetext{
* Corresponding author: Bert Blocken, Building Physics and Services, Eindhoven University of Technology, P.O.Box 513, 5600 MB Eindhoven, the Netherlands. Tel.: +31 (0)40 247 2138, Fax +31 (0)40 2438595

E-mail address: b.j.e.blocken@tue.nl
} 
While most aerodynamic studies in cycling focused on the drag of a single (isolated) cyclist, several efforts have also been made to assess the effects of "drafting" (Kyle 1979, McCole et al. 1990, Hagberg and McCole 1990, Zdravkovich et al. 1996, Olds 1998, Broker et al. 1999, Edwards and Byrnes 2007, Iniguez-de-la-Torre and Iniguez 2009, Blocken et al. 2013). In drafting, two or more cyclists ride close behind each other to reduce aerodynamic drag. This way, the trailing cyclist can benefit from the low pressure area behind the leading cyclist. Note that the focus of most of these studies was on the effects of the leading cyclist on the trailing cyclist, and not of the trailing one on the leading one. Concerning the latter aspect, Olds (1998) provided the following statement:

"It has been suggested that riding close behind a leading cyclist will also assist the leading rider in that the low pressure area behind the cyclist will be "filled up" by the trailing rider. However, both Kyle (1979) and McCole et al. (1990) failed to find any measurable effect either in rolldown experiments or in field $\mathrm{VO}_{2}$ measurements."

In 2013, Blocken et al. ascertained and quantified the upstream effect by a trailing rider on a leading rider. They performed CFD simulations with the steady Reynolds-Averaged Navier-Stokes (RANS) equations and the standard k- $\varepsilon$ model for three different cyclist positions (Upright position, Dropped position, Time-trial position) and for a range of separation distances between leading and trailing rider $(\mathrm{d}=0.25 \mathrm{~m}, \mathrm{~d}=0.5 \mathrm{~m}, \mathrm{~d}=1 \mathrm{~m}$, etc). For all positions, they found substantial drag reductions for the leading rider, up to $2.7 \%$ for the time-trial position. Inspired by the above-quoted argumentation by Olds (1998), they investigated the pressure fields between the leading and trailing cyclist, indeed revealing the mechanism as suggested by Olds (1998) and also providing further insights. The CFD simulations clearly indicated that the overpressure zone in front of the trailing rider interacts with the underpressure zone behind the leading rider, thereby reducing not only the size, but also the magnitude of the negative pressures in this zone. As a result, the drag of the leading rider reduces substantially, up to $2.7 \%$ for a distance of $0.01 \mathrm{~m}$. While a distance of $0.01 \mathrm{~m}$ might seem unrealistic, it should be noted that it is not, as riders often ride in slightly staggered position with the rear wheel of the leading rider almost next to the front wheel of the trailing rider, which actually is closer together than the $0.01 \mathrm{~m}$ distance wheel-to-wheel.

Extrapolating from these earlier findings, in this paper we set out to explore the aerodynamic impact by a following car on the drag of an elite cyclist. Note that the term "following car" is adopted from the rules and terminology of the International Cycling Union (UCI). As a car is a much larger body, thereby generating a much larger overpressure in front of it, the aerodynamic effect by the following car is expected to be much more pronounced compared to that of a trailing cyclist. It is well-known in elite cycling that a cyclist riding behind a car experiences a substantial reduction in drag. However, the upstream effect of a following car on the cyclist in front of it is not well-known and has, to the best of our knowledge, not yet been reported in the scientific literature. It is also not taken into account in elite cycling, as for individual time trials, the rules of the UCI only specify a minimum distance between rider and car of $10 \mathrm{~m}$ because of safety reasons (UCI 2015). Furthermore, during actual races, this limit is often not kept and not strictly enforced. Nevertheless, during individual time trials, there is always at least one, but often more following cars, potentially influencing the drag of the cyclist. The methodology employed in this study consists of a combination of CFD simulations and reduced-scale wind tunnel measurements.

\section{Wind tunnel experiments for cyclist and following car}

The experiments were performed in the low-speed closed-circuit wind tunnel VKI L-1B of the Von Karman Institute for Fluid Dynamics in Sint-Genesius-Rode, Belgium. The test section of the tunnel is $3 \mathrm{~m}$ wide and $2 \mathrm{~m}$ high. The full-scale dimensions of cyclist, bicycle and following car (typical station wagon team car) are given in Figure 1. Digital models of the cyclist were obtained with high-resolution 3D laser scanning (K-Scan, Nikon Metrology, Belgium) capturing the specific body characteristics of a given elite cyclist in time-trial position. The height and the weight of the cyclist were $183 \mathrm{~cm}$ and $72 \mathrm{~kg}$, respectively. He was equipped with an aerodynamic helmet, glasses, gloves and a standard tight-fitting racing suit with long sleeves. In time-trial position, the frontal area was $0.34 \mathrm{~m}^{2}$. The bicycle is a standard racing bicycle with open wheel at the front and disk wheel at the rear and a time-trial handlebar. Both wheels are fixed. To fully accommodate the body of the car in the wind tunnel at a blockage ratio below $3 \%$, the models of cyclist, bicycle and car were manufactured at the scale $1 / 4$, yielding a blockage ratio of $2.7 \%$. The set-up of the models is shown in Figure 2 . The velocity profile in the test section was uniform except for the boundary layers on the walls. The force platform with the bicycle and cyclist was positioned at the immediate exit of the wind tunnel contraction, i.e. at the entrance of the wind tunnel test section, to limit boundary layer development. The platform was set at $0.02 \mathrm{~m}$ from the lower wind tunnel wall, for the bicycle to be outside of the steepest part of the boundary layer on this wall, because this boundary layer is also not present in reality, i.e. on the road surface, if there is no wind flow. 
Measurements were performed at different approach-flow reference wind speed values, ranging from 5over 10 to $15 \mathrm{~m} / \mathrm{s}$, at which Reynolds number independence was achieved. The nominal turbulence intensity at the inlet of the test section was $2 \%$. Note that the approach-flow conditions of very low turbulence intensity in the wind tunnel tests in this study and in most other wind tunnel experiments on cyclist aerodynamics (i.e. uniform mean velocity profile and low turbulence intensity) are representative for the case where only the cyclist is moving and where the speed of the surrounding air is zero. This situation is typically found in indoor environments (e.g. a velodrome) or outdoor in the absence of wind. Measurements were performed for separation distances, measured between rear wheel and front car bumper, of $\mathrm{d}=1,2,3,4,5$ and $8 \mathrm{~m}$.

Drag in cycling is often quantified by the drag area $\mathrm{AC}_{\mathrm{D}}\left(\mathrm{m}^{2}\right)$, which is the product of the frontal area of the cyclist $(A)$ and the drag coefficient $\left(C_{D}\right)$. It relates the drag force $\left(F_{D}\right)$ to the dynamic pressure $\left(\rho U_{\infty}{ }^{2} / 2\right)$ :

$\mathrm{F}_{\mathrm{D}}=\mathrm{AC}_{\mathrm{D}} \frac{\rho \mathrm{U}_{\infty}^{2}}{2}$

where $\rho$ is the density of air $\left(\mathrm{kg} / \mathrm{m}^{3}\right)$ and $U_{\infty}$ the approach-flow air speed $(\mathrm{m} / \mathrm{s})$. The drag force, i.e. the horizontal component parallel to the wind direction and bicycle, was measured using a force transducer with a precision of $0.05 \mathrm{~N}$. The data were sampled at $2 \mathrm{kHz}$ for $10 \mathrm{~s}$. The measurements were made at $1.018 \mathrm{bar}$ and $1.23 \mathrm{~kg} / \mathrm{m}^{3}$. The measurement results will be reported together with the simulation results in the next sections.

\section{CFD simulations: computational settings and parameters}

\subsection{Computational geometry and domain}

For grid generation, surface details in the geometrical model were smoothed out to some extent and the bicycle was simplified. Simulations were performed for separation distances d =1, 2, 3, 5, 7.5, 8, 10, 12, 15 and $20 \mathrm{~m}$. Full-scale and reduced-scale simulations gave identical results, therefore only full-scale simulations are reported in the remainder of this paper.

The cyclist and car were placed in a computational domain with size according to best practice guidelines (Franke et al. 2007, Tominaga et al. 2008). The size of the computational domain was $\mathrm{L} \times \mathrm{W} \times \mathrm{H}=33.45 \times 16.8$ $\mathrm{x} 9.45 \mathrm{~m}^{3}$ for $\mathrm{d}=1 \mathrm{~m}$. For the other separation distances, the length $\mathrm{L}$ of the computational domain was extended accordingly. The maximum blockage ratio was $1.6 \%$, which is well below the recommended maximum value of $3 \%$ (Franke et al. 2007, Tominaga et al. 2008). The distance of the inlet plane to the single or leading cyclist was chosen sufficiently large (i.e. $7.52 \mathrm{~m}$ ) in order to avoid pressure gradients in/near the inlet plane.

\subsection{Computational grid}

The grids were based on grid-sensitivity analysis and grid generation guidelines in CFD (Casey and Wintergerste 2000, Franke et al. 2007, Tominaga et al. 2008). A high resolution of cells was used in the boundary-layer region, with the wall-adjacent cell center point at only $30 \mu \mathrm{m}$ from the body surface. This was needed to allow proper employment of the (scalable) wall functions based on the dimensionless wall unit $\mathrm{y}^{*}$, which was kept in the range between 4 and 334. The dimensionless wall unit is defined as:

$$
\mathrm{y}^{*}=\frac{\mathrm{u}^{*} \mathrm{y}_{\mathrm{P}}}{v}
$$

where $\mathrm{u}^{*}$ is a friction velocity based on the turbulent kinetic energy $\mathrm{k}_{\mathrm{P}}$ in the wall-adjacent cell centre point $\mathrm{P}$ and on the constant $\mathrm{C}_{\mu}(=0.09)$ :

$$
\mathrm{u}^{*}=\mathrm{C}_{\mu}^{1 / 4} \mathrm{k}_{\mathrm{P}}^{1 / 2}
$$

Note that often the parameters $\mathrm{y}^{+}$and $\mathrm{u}^{+}$are used instead of $\mathrm{y}^{*}$ and $\mathrm{u}^{*}$. However, the alternatively defined parameters $\mathrm{y}^{*}$ and $\mathrm{u}^{*}$ have the advantage that they allow to specify grid resolution requirements even at locations in the flow field where the shear stress $\tau_{\mathrm{w}}$ is zero, which occurs at stagnation and reattachment points, i.e. at the cyclists arms, legs, chest, face and helmet. In that case, $\mathrm{y}^{+}$is zero irrespective of the local grid resolution $\mathrm{y}_{\mathrm{P}}$, and cannot be used to specify the grid requirements The alternative parameter $\mathrm{y}^{*}$, however, will not be zero because it is based on $\mathrm{k}_{\mathrm{P}}$ (Casey and Wintergerste 2000, Blocken et al. 2009, Defraeye et al. 2010). While $60 \mu \mathrm{m}$ cells are used at the body surface, further away from the surface, tetrahedral cells were used with 
an average cell size of about $0.02 \mathrm{~m}$, and hexahedral cells with a cell size of $0.02 \mathrm{~m}$ and more. The grids for the cyclist and car configurations contained about $27.9 \times 10^{6}$ cells. Figure $4 \mathrm{a}-\mathrm{c}$ display part of the grids. The footprints of the cells on the cyclist bodies and the cells in the vertical centerplane are shown. The figures illustrate the very high grid resolution close to the body.

\subsection{Boundary conditions}

At the inlet, a uniform velocity of $15 \mathrm{~m} / \mathrm{s}$ was imposed with a turbulence intensity of $1 \times 10^{-6} \%$, representing the relative air movement due to cycling at this velocity in still air (zero wind speed). The cyclist body surface was modeled as a no-slip boundary wall with zero roughness, at which scalable wall functions were assigned (Grotjans and Menter 1998). Note that some recent studies on cyclist aerodynamics used low-Reynolds number modelling (LRNM) instead of wall functions (Defraeye et al. 2010a, 2010b, 2011, 2014, Blocken et al. 2013). In the present study however, some parts of the near-wall grid are too coarse for LRNM. For the bottom, side and top boundaries of the domain, a slip-wall boundary (symmetry) was used. Slip walls assume that the normal velocity component and the normal gradients at the boundary are zero, resulting in flow parallel to the boundary. At the outlet of the computational domain, ambient static pressure was imposed.

\subsection{Governing equations and solver settings}

The 3D steady RANS equations were solved with the standard k- $\varepsilon$ model (Jones and Launder 1972) for closure. The choice of the standard $\mathrm{k}-\varepsilon$ model was made based on a previous extensive validation study for the aerodynamics of a single cyclist, including the standard, realizable and Re-normalization Group (RNG) k- $\varepsilon$ model, the standard k- $\omega$ model, the Shear-Stress Transport (SST) k- $\omega$ model and Large Eddy Simulation. This study, reported in (Defraeye et al. 2010b), showed that the k- $\varepsilon$ model most accurately predicted the drag, with an underestimation of $4 \%$ compared to the corresponding wind tunnel result.

Pressure-velocity coupling was taken care of by the SIMPLEC algorithm, pressure interpolation was second order and second-order discretisation schemes were used for both the convection terms and the viscous terms of the governing equations. Gradients are computed with the least-squares cell-based method (Ansys 2013), which is different from earlier simulations in cycling aerodynamics that used the Green-Gauss cell-based method (Defraeye et al. 2010a, 2010b). The simulations were performed with the commercial CFD code ANSYS Fluent 15 (Ansys 2013) which uses the control volume method. Convergence was monitored carefully and the iterations were terminated when all residuals showed no further reduction with increasing number of iterations. At this stage, the scaled residuals were about $10^{-4}$ for continuity, $10^{-7}$ for momentum, $10^{-5}$ for turbulent kinetic energy and $10^{-5}$ for turbulence dissipation rate.

\section{CFD simulations: results}

\subsection{Drag reductions and validation}

Figure 5 displays the CFD results and the wind tunnel results in terms of drag reduction of the system "cyclist and bicycle", relative to the case without a following car present. The drag reduction due to the presence of a following car at $\mathrm{d}=1 \mathrm{~m}$ reaches above $13 \%$ but it rapidly decreases with increasing separation distance. The average deviation between the CFD simulations and the wind tunnel measurements is $0.1 \%$ of drag reduction. The numerical values of the drag reduction from the CFD simulations are given in Table 1.

\subsection{Analysis of pressure fields}

Figure 6 shows the pressure coefficient $C_{p}$ in the vertical centerplane for the cyclist and the following car at 12 separation distances. Figure 7 shows the same, but in a horizontal plane at waist height of the cyclist. The pressure coefficient is defined as:

$$
\mathrm{C}_{\mathrm{P}}=2 \frac{\mathrm{P}-\mathrm{P}_{0}}{\rho \mathrm{U}_{\infty}^{2}}
$$

where $\mathrm{P}$ is the static pressure and $\mathrm{P}_{0}$ the reference static pressure (= atmospheric pressure). The legend in Figures 6 and 7 has been limited to the interval $[-0.025 ; 0.025]$, to more clearly highlight the changes in the static pressure field. Note that the actual maximum and minimum (absolute) values of $\mathrm{C}_{\mathrm{p}}$ are much larger. The figures clearly show the area of overpressure in front of the cyclist and the area of underpressure behind the cyclist. 
They also show the much larger area of overpressure in front of the car, and the much larger area of underpressure above the car. When the distance between cyclist and car decreases, the overpressure area in front of the car more strongly interacts with the underpressure area behind the cyclist, thereby reducing this underpressure area.

Figure 8 and 9 show the pressure coefficient on the surface of cyclist body and bicycle, illustrating that the absolute value of the underpressure on these surfaces decreases as the car is positioned closer to the cyclist. This explains the - at first sight maybe counterintuitive - observation that the presence of a following car decreases the drag of the cyclist.

\section{Potential impact on individual time trials}

We developed a nomogram, shown in Figure 10, that indicates the time reduction (compared to the case of cyclist without following car) in an individual time trial. The horizontal axis contains the time trial distance, and the separation distance $\mathrm{d}$ between cyclist and car is used as a parameter. It can be seen that for a typical time trial distance of $50 \mathrm{~km}$ and for realistic separation distances 3,5 and $10 \mathrm{~m}$, the potential time reduction by exploiting the aerodynamic effect by the following car is $62.4 \mathrm{~s}, 24.1 \mathrm{~s}$ and $3.9 \mathrm{~s}$, respectively. It should be noted however that the nomogram is based on the geometrical characteristics of the cyclist, bicycle and car and on zero wind speed conditions. Different geometrical characteristics and different wind speed conditions will yield different nomograms.

As elite cyclist time trials are often won based on seconds or sometimes even less, these differences can be decisive for who wins the stage. Therefore, it is recommended that the UCI not only raises its current minimum separation distance of $10 \mathrm{~m}$ to at least $30 \mathrm{~m}$, but also strictly enforces it, to avoid this unwanted aerodynamic effect that can influence the outcome of the race. While $30 \mathrm{~m}$ might seem a large distance, it should be noted that the time reduction with this separation distance for an individual time trial of $50 \mathrm{~km}$ still corresponds to $0.3 \mathrm{~s}$.

\section{Discussion}

To the best knowledge of the authors, the impact of a following car on the drag of a cyclist has not yet been investigated in the scientific literature. The present study is based on high-resolution CFD simulations and on validation with wind-tunnel measurements. Both CFD simulations and wind tunnel measurements allowed to ascertain and quantify the substantial drag reduction exerted by a following car on a cyclist. However, the present study is also subjected to some important limitations, which are briefly mentioned below, together with some directions for future research.

A main limitation of the study is that the bicycle wheels and cyclist legs were stationary, so only static air resistance was considered. This is important, because under normal circumstances the rotation of the legs disturbs the airstream. Future research should focus on analysing the drag reductions at different pedalling frequencies.

The present study only considered a single geometry of cyclist, bicycle and car. Further research can include cyclists of different height and weight, and with different positions on the bicycle. Although the car geometry chosen was that of a typical team car, further research could also include different car types.

Finally, all simulations were performed assuming zero wind speed conditions, i.e. the movement of air was only due to the movement of the cyclist, bicycle and car in still air. Further studies should investigate the effects of cross wind on the aerodynamic interaction between cyclist and following car.

\section{Summary and conclusions}

It is well-known in elite cycling that a cyclist riding behind a car experiences a substantial reduction in drag. However, the upstream effect of a following car on the cyclist in front of it is not well-known and has, to the best of our knowledge, not yet been reported in the scientific literature.

This study presents the results of CFD simulations and wind tunnel measurements to ascertain and quantify the upstream effect by a following car on the drag of the cyclist. CFD simulations are performed based on the steady-state Reynolds-Averaged Navier-Stokes equations with the standard k- $\varepsilon$ model for closure. The simulations are validated based on a series of wind tunnel measurements. The drag reduction for the cyclist ranges from $3.7 \%$ over $1.4 \%$ to $0.2 \%$ for realistic separation distances of 3,5 and $10 \mathrm{~m}$, respectively. The CFD simulations allow to investigate the static pressure field. Especially for low separation distances $(\mathrm{d}<10 \mathrm{~m})$, there is a clear interaction between the overpressure zone in front of the car and the underpressure zone behind the cyclist. This interaction leads to less pronounced underpressure behind the cyclist, and therefore to a lower drag of the cyclist. Based on the CFD simulations, a nomogram was developed that allows to assess the time reduction that can be obtained in an individual time trial by a cyclist closely followed by a team car, versus a cyclist not followed by a car, or only at a much larger distance. For a typical $50 \mathrm{~km}$ individual time trial, the 
potential time reduction by exploiting the drag reduction by the car is $62.4 \mathrm{~s}, 24.1 \mathrm{~s}$ and $3.9 \mathrm{~s}$, respectively. As elite cyclist time trials are often won based on seconds or sometimes even less, these differences can be decisive for who wins the stage.

To the best of our knowledge, this effect is not taken into account in elite cycling, as for individual time trials, the rules of the International Cycling Union (UCI) only specify a minimum distance between rider and car of 10 $\mathrm{m}$ because of safety reasons. Furthermore, during actual races, this limit is often not kept and not strictly enforced. During individual time trials, there is always at least one, but often more following cars, potentially influencing the aerodynamic resistance of the cyclist. Therefore, it is recommended that the UCI not only raises its current minimum separation distance of $10 \mathrm{~m}$ to at least $30 \mathrm{~m}$, but also strictly enforces it, to avoid this unwanted aerodynamic effect that can influence the outcome of the race.

\section{Acknowledgements}

The authors acknowledge the support by Ir. Thierry Marchal, Global Industry Director for Sports at ANSYS Inc. and the support by Prof.dr.ir. Jeroen van Beeck and ir. Gertjan Glabeke from the von Karman Institute for Fluid Dynamics in Sint-Genesius-Rode, Belgium.

\section{References}

ANSYS Fluent, Release 15.0, Theory Guide, November 2013, ANSYS Inc.

Blocken, B., Carmeliet, J. 2004. A review of wind-driven rain research in building science. Journal of Wind Engineering and Industrial Aerodynamics, 92 (13), 1079-1130.

Blocken B, Defraeye T, Derome D, Carmeliet J. 2009. High-resolution CFD simulations of forced convective heat transfer coefficients at the facade of a low-rise building. Build Environ 44(12): 2396-2412.

Blocken B, Defraeye T, Koninckx E, Carmeliet J, Hespel P. 2013. CFD simulations of the aerodynamic drag of two drafting cyclists. Computers \& Fluids 71: 435-445.

Blocken B. 2014. 50 years of Computational Wind Engineering: Past, present and future. Journal of Wind Engineering and Industrial Aerodynamics 129: 69-102.

Blocken B. 2015. Computational Fluid Dynamics for Urban Physics: Importance, scales, possibilities, limitations and ten tips and tricks towards accurate and reliable simulations. Building and Environment 91: 219-245.

Britter, R., Schatzmann, M. (Eds.). 2007. Model Evaluation Guidance and Protocol Document COST Action 732. COST Office Brussels, ISBN 3-00-018312-4.

Broker JP, Kyle CR, Burke ER. 1999. Racing cyclist power requirements in the 4000-m individual and team pursuits, Med Sci Sports Exercise 31 (11), 1677-1685.

Casey M, Wintergerste T. 2000. Best Practice Guidelines. ERCOFTAC Special Interest Group on "Quality and Trust in Industrial CFD", ERCOFTAC.

Defraeye T, Blocken B, Carmeliet J. 2010. CFD analysis of convective heat transfer at the surfaces of a cube immersed in a turbulent boundary layer. International Journal of Heat and Mass Transfer 53(13), 297-308.

Defraeye T, Blocken B, Koninckx E, Hespel P, Carmeliet J. 2010a. Aerodynamic study of different cyclist positions: CFD analysis and full-scale wind-tunnel tests. J Biomech 43(7), 1262-1268.

Defraeye T, Blocken B, Koninckx E, Hespel P, Carmeliet J. 2010b. Computational Fluid Dynamics analysis of cyclist aerodynamics: Performance of different turbulence-modelling and boundary-layer modelling approaches. J Biomech 43(12), 2281-2287.

Defraeye T, Blocken B, Koninckx E, Hespel P, Carmeliet J. 2011. Computational fluid dynamics analysis of drag and convective heat transfer of individual body segments for different cyclist positions. $\mathrm{J}$ Biomech 44(9), 1695-1701.

Defraeye T, Blocken B, Koninckx E, Hespel P, Verboven P, Nicolai B, Carmeliet J. 2014. Cyclist drag in team pursuit: influence of cyclist sequence, stature, and arm spacing. Journal of Biomechanical EngineeringASME 136 (1), art. no. 011005

Edwards AG, Byrnes WC. 2007. Aerodynamic characteristics as determinants of the drafting effect in cycling. Med Sci Sports Exercise 39(1), 170-176.

Franke J, Hellsten A, Schlünzen H, Carissimo B. 2007. Best practice guideline for the CFD simulation of flows in the urban environment, COST Action 732: Quality assurance and improvement of microscale meteorological models, Hamburg, Germany.

Grappe G, Candau R, Belli A, Rouillon JD. 1997. Aerodynamic drag in field cycling with special reference to the Obree's position. Ergonomics 40(12), 1299-1311. 
Grotjans H, Menter F. 1998. Wall functions for general application CFD codes," in Proceedings of the 4th Computational Fluid Dynamics Conference (ECCOMAS '98), pp. 1112-1117, John Wiley \& Sons.

Hagberg JM, McCole SD. 1990. The effect of drafting and aerodynamic equipment on the energy expenditure during cycling. Cycling Science 2(3), 19-22.

Hanna RK. 2002. Can CFD make a performance difference in sport?. In: Ujihashi, S., Haake, S.J. (Eds.), The Engineering of Sport 4. Blackwell Science, Oxford, pp. 17-30.

Iniguez-de-la-Torre A, Iniguez J. 2009. Aerodynamics of a cycling team in a time trial: does the cyclist at the front benefit? Eur J Phys 30: 1365-1369.

Jones WP, Launder BE. 1972. The prediction of laminarization with a two-equation model of turbulence. Int J Heat Mass Transfer 15, 301-314.

Kyle CR, Burke ER. 1984. Improving the racing bicycle. Mech Eng 106(9), 34-45.

Kyle CR. 1979. Reduction of wind resistance and power output of racing cyclists and runnings travelling in groups. Ergonomics 22(4), 387-397.

Lukes RA, Chin SB, Haake SJ. 2005. The understanding and development of cycling aerodynamics. Sports Eng 8, 59-74.

Lukes RA, Hart JH, Chin SB, Haake SJ. 2004. The aerodynamics of mountain bicycles: The role of computational fluid dynamics. In: Hubbard M, Mehta RD, Pallis JM. (Eds.), The Engineering of Sport 5. International Sports Eng Association, Sheffield.

McCole SD, Claney K, Conte J-C, Anderson R, Hagberg JM. 1990. Energy expenditure during bicycling. J Appl Physiol 68(2), 748-753.

Meroney, R.N. 2004. Wind tunnel and numerical simulation of pollution dispersion: a hybrid approach. Paper for Invited Lecture at the Croucher Advanced Study Institute, Hong Kong University of Science and Technology, 6-10 December 2004.

Mochida, A., Lun, I.Y.F. 2008. Prediction of wind environment and thermal comfort at pedestrian level in urban area. Journal of Wind Engineering and Industrial Aerodynamics, 96 (10-11), 1498-1527.

Murakami, S. 1997. Current status and future trends in computational wind engineering. Journal of Wind Engineering and Industrial Aerodynamics 67 and 68: 3-34.

Murakami, S., Ooka, R., Mochida, A., Yoshida, S., Kim, S. 1999. CFD analysis of wind climate from human scale to urban scale. Journal of Wind Engineering and Industrial Aerodynamics, 81(1-3), 57-81.

Olds T. 1998. The mathematics of breaking away and chasing in cycling. Eur J Appl Physiol 77: 492-497.

Stathopoulos, T. 1997. Computational Wind Engineering: Past achievements and future challenges. Journal of Wind Engineering and Industrial Aerodynamics 67-68: 509-532.

Stathopoulos, T. 2002. The numerical wind tunnel for industrial aerodynamics: real or virtual in the new millennium? Wind and Structures, 5 (2-4), 193-208.

Tominaga Y, Mochida A, Yoshie R, Kataoka H, Nozu T, Yoshikawa M, Shirasawa T. 2008. AIJ guidelines for practical applications of CFD to pedestrian wind environment around buildings. J Wind Eng Ind Aerodyn 96(10-11), 1749-1761.

Tominaga, Y., Stathopoulos, T. 2013. CFD simulation of near-field pollutant dispersion in the urban environment: A review of current modelling techniques. Atmospheric Environment, 79, 716-730.

International Cycling Union 2015. UCI Cycling Regulations, Part 2, Road Races, Version 05.02.2015.

Wilson DG. 2004. Bicycling science. Third Edition, Cambridge, MA: MIT Press.

Zdravkovich MM, Ashcroft MW, Chisholm SJ, Hicks N. 1996. Effect of cyclist's posture and vicinity of another cyclist on aerodynamic drag. The Engineering of Sport. Haake (Ed.), Balkema, Rotterdam, pp. 21-28. 


\section{FIGURES AND TABLES}
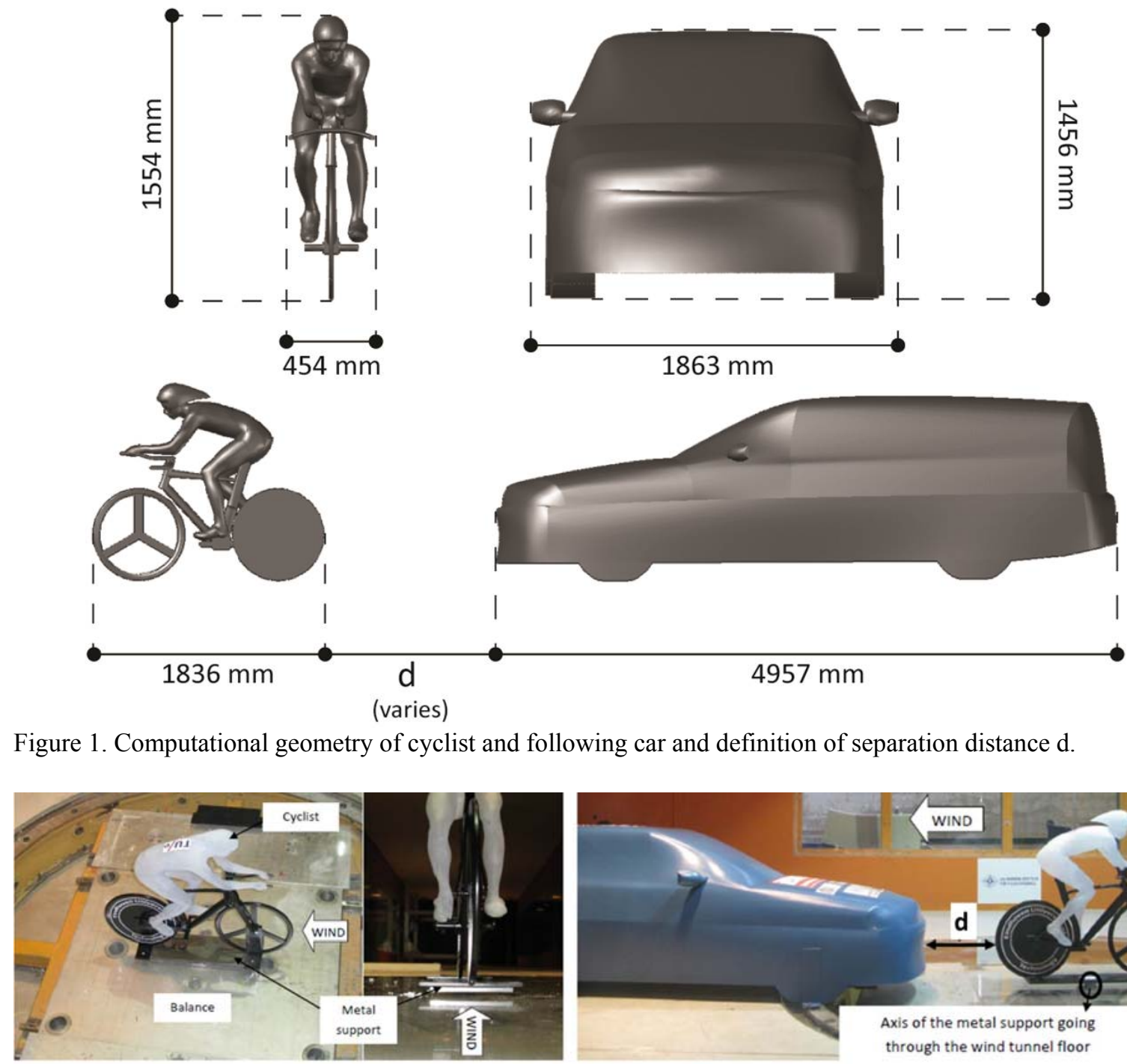

$4957 \mathrm{~mm}$

(varies)

Figure 1. Computational geometry of cyclist and following car and definition of separation distance d.

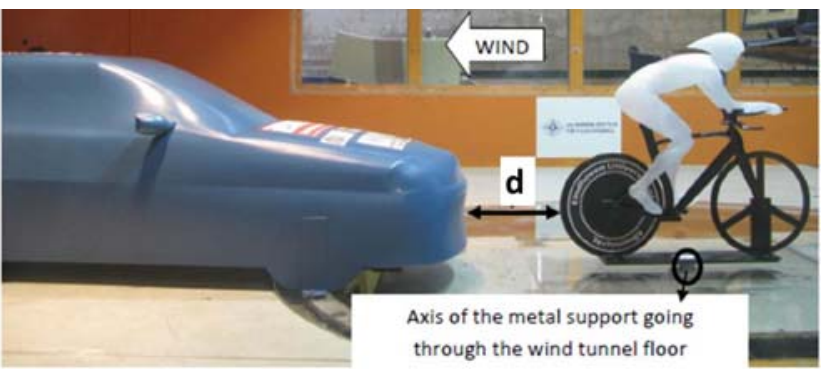

Figure 2. Set-up of model of cyclist and car in the wind tunnel. 


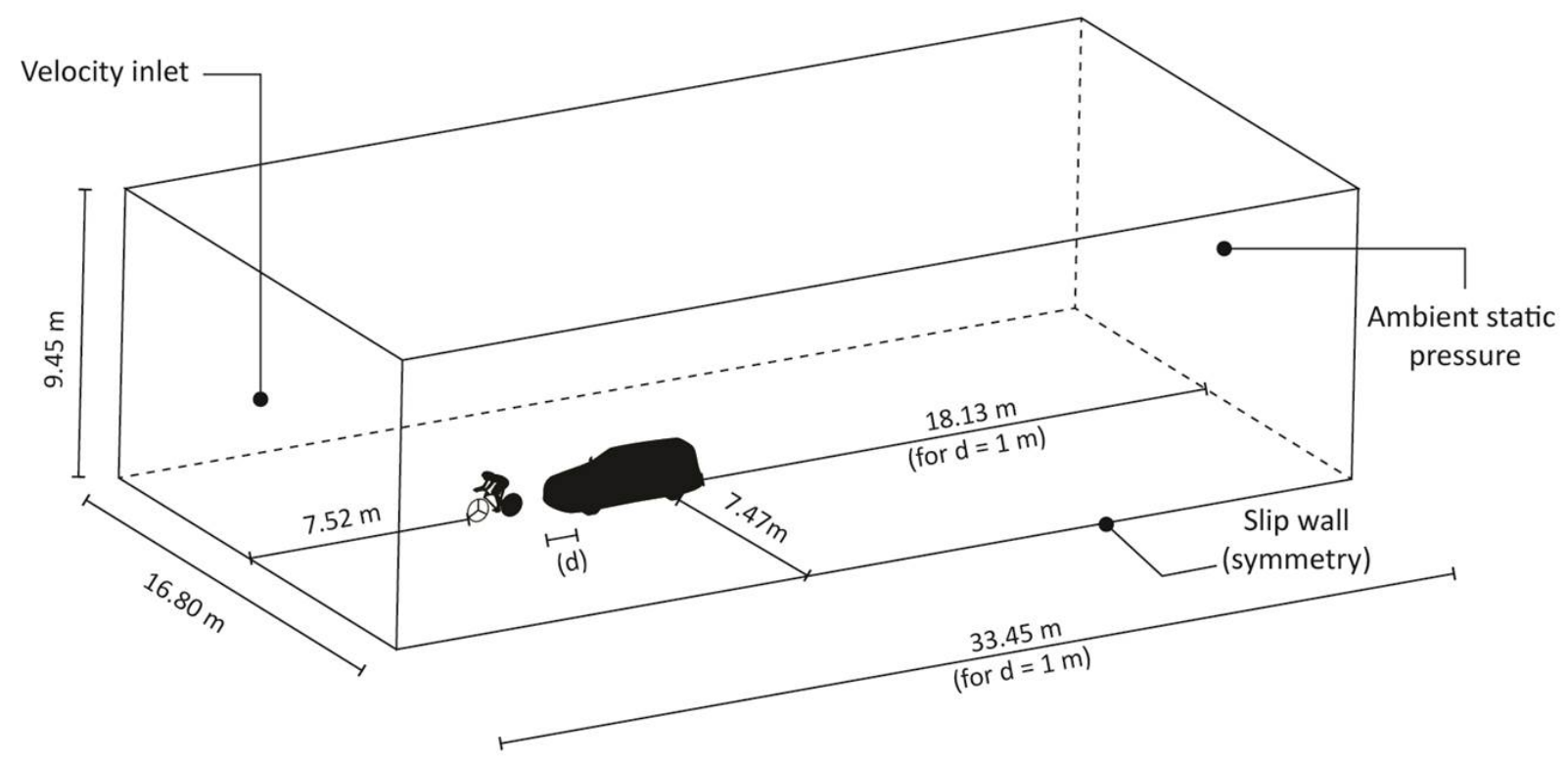

Figure 3. Computational domain

a)

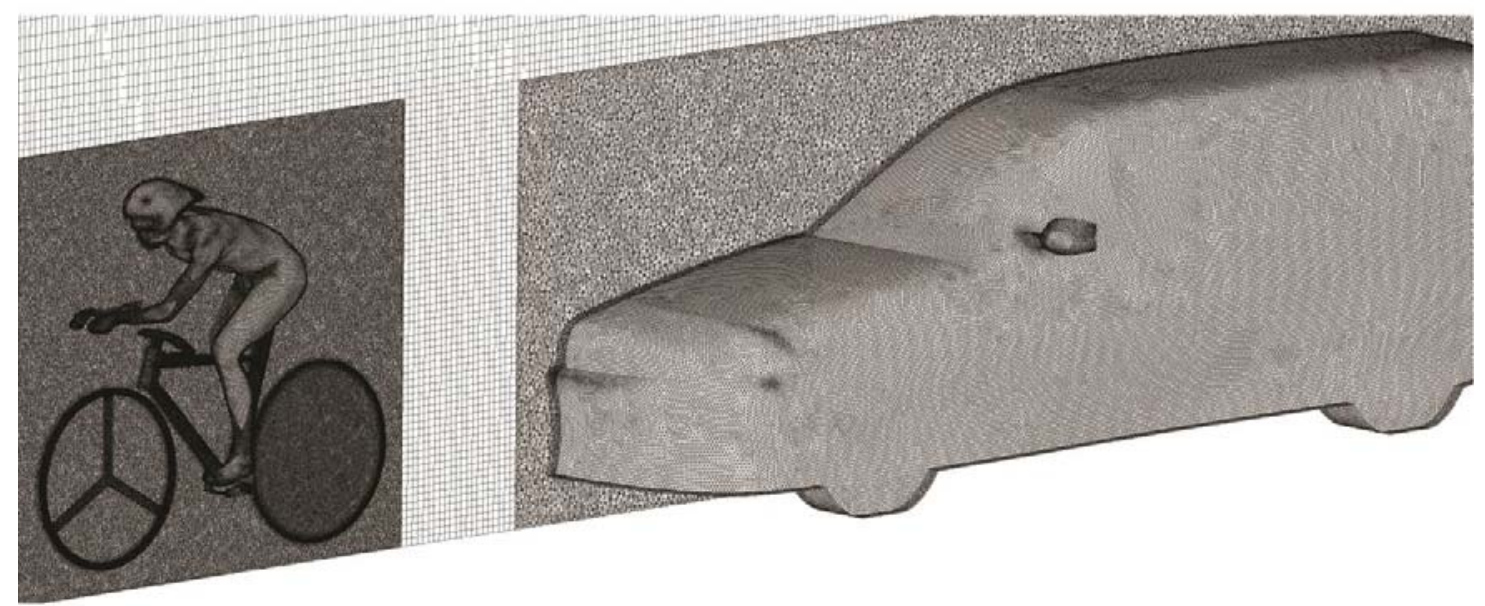

b)

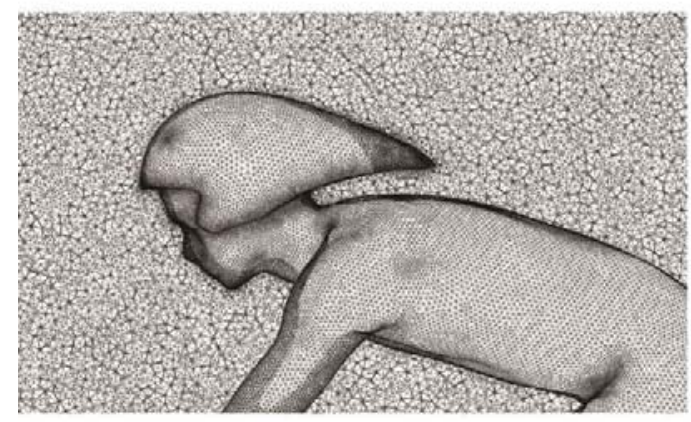

c)

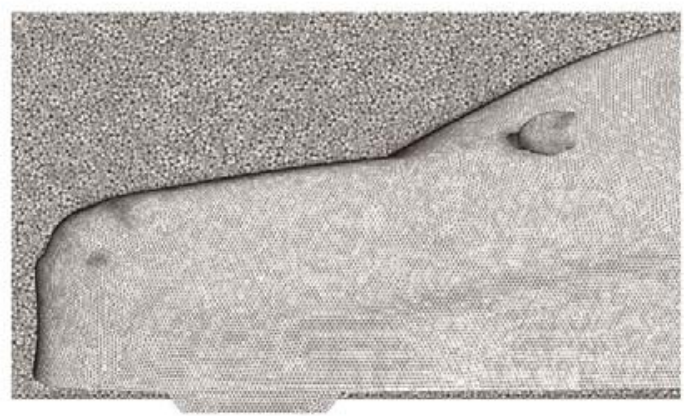

Figure 4. Hybrid computational grid on cyclist, bicycle and car in vertical centerplanes for a separation distance $\mathrm{d}=1 \mathrm{~m}$. 


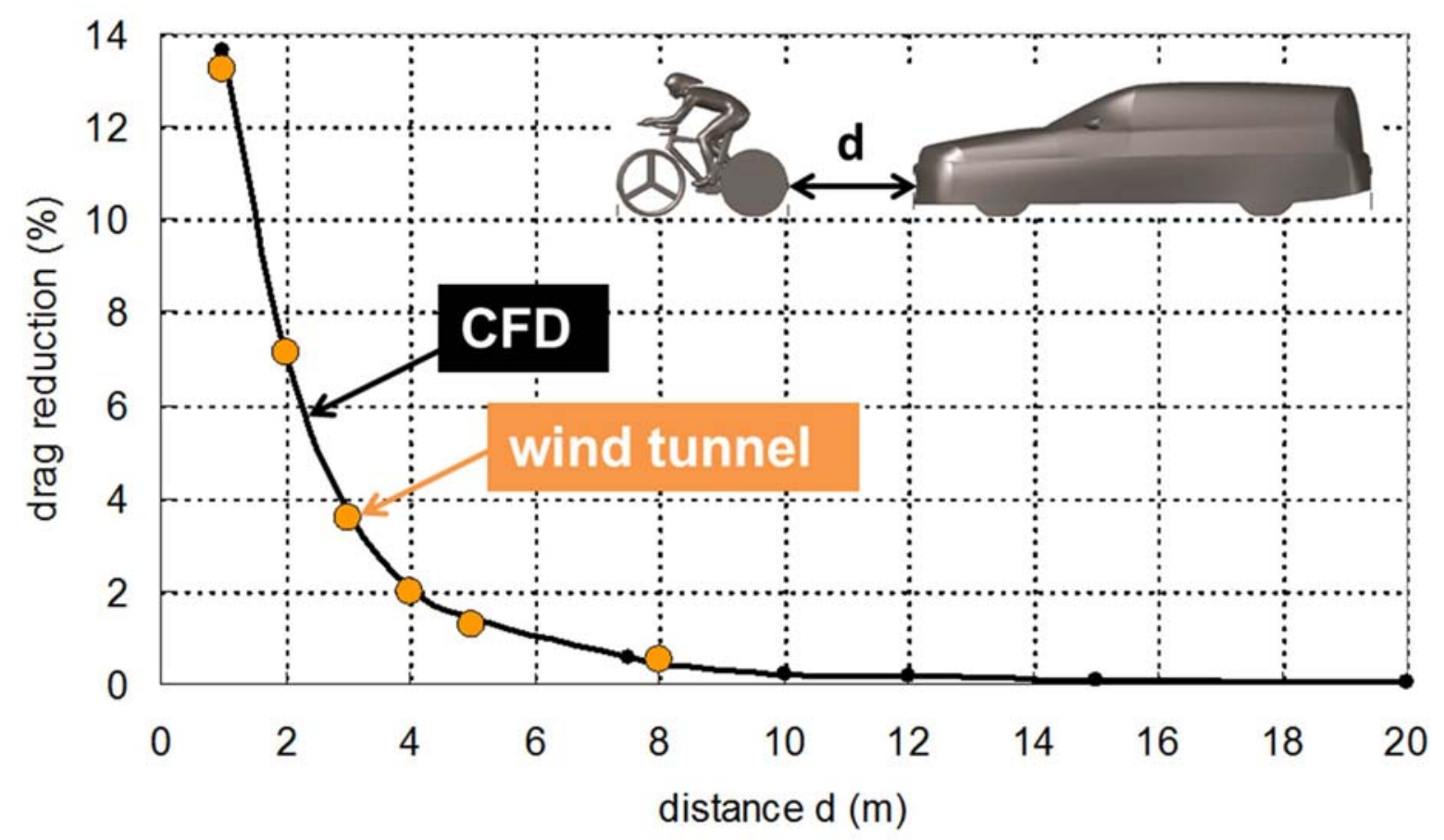

Figure 5. Drag reduction of cyclist due to presence of car by CFD simulations and wind tunnel measurements. 


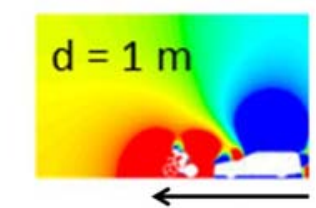

$d=2 m$

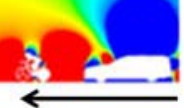

$\mathrm{d}=3 \mathrm{~m}$

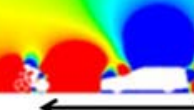

$\mathrm{d}=4 \mathrm{~m}$
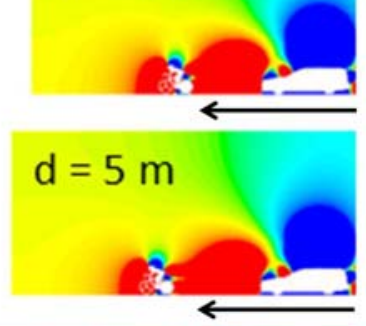

$\mathrm{d}=8 \mathrm{~m}$

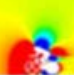

$$
d=10 m
$$

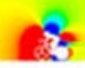

$$
\mathrm{d}=12 \mathrm{~m}
$$

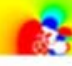

$$
d=15 m
$$

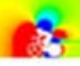

$$
d=20 m
$$

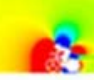

$$
d=25 m
$$

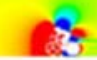

$d=30 m$

\section{8}

\section{Pressure Coefficient $\left(C_{p}\right)$}

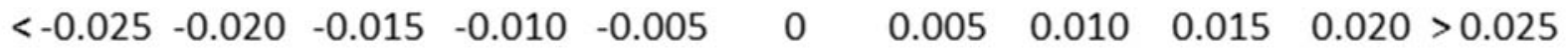

Figure 6. Pressure coefficients $C_{P}$ in the vertical centerplane for cyclist followed by car for separation distances from $\mathrm{d}=1 \mathrm{~m}$ up to $30 \mathrm{~m}$, at cycling speed of $15 \mathrm{~m} / \mathrm{s}(=54 \mathrm{~km} / \mathrm{h})$. 

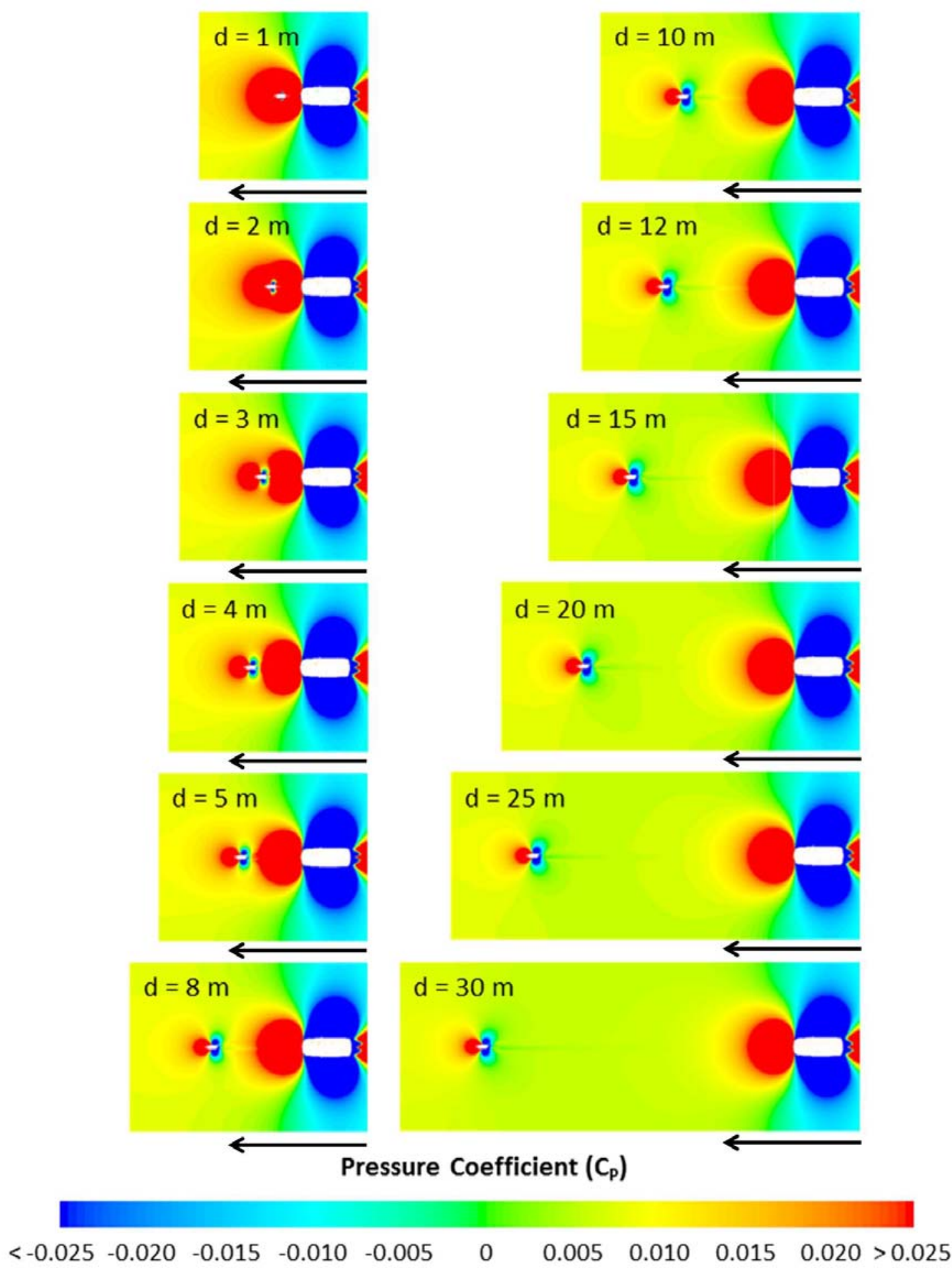

Figure 7. Pressure coefficients $C_{P}$ in the horizontal plane at waist height of the cyclist followed by car for separation distances from $\mathrm{d}=1 \mathrm{~m}$ up to $30 \mathrm{~m}$, at cycling speed of $15 \mathrm{~m} / \mathrm{s}(=54 \mathrm{~km} / \mathrm{h})$. 

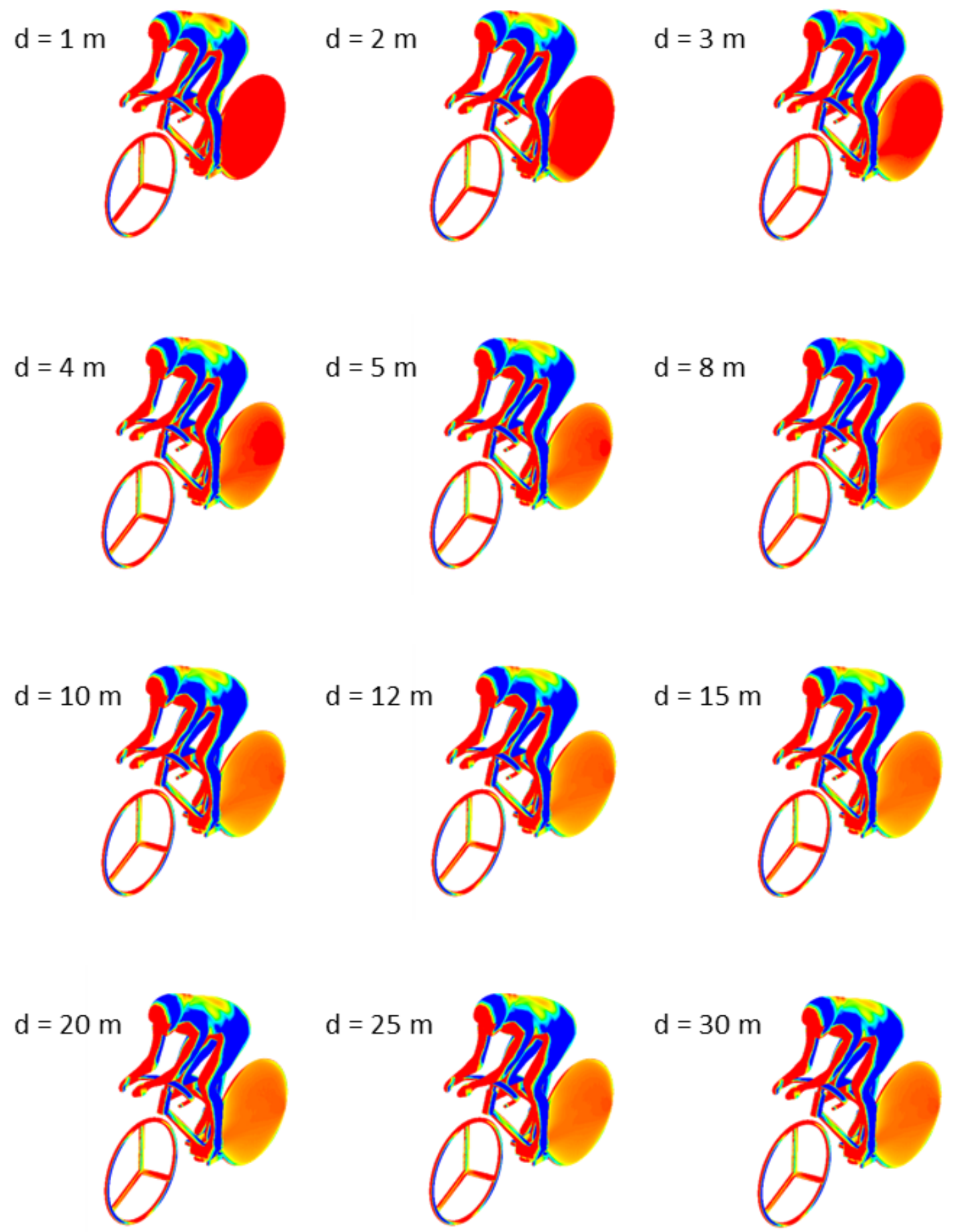

\section{Pressure Coefficient $\left(C_{p}\right)$}

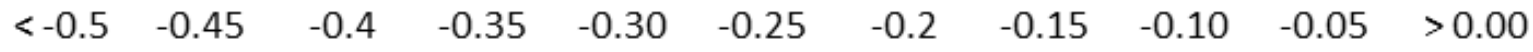

Figure 8. Pressure coefficients $\mathrm{C}_{\mathrm{P}}$ on the body of the cyclist and bicycle followed by car for separation distances from $\mathrm{d}=1 \mathrm{~m}$ up to $30 \mathrm{~m}$, at cycling speed of $15 \mathrm{~m} / \mathrm{s}(=54 \mathrm{~km} / \mathrm{h})$. 

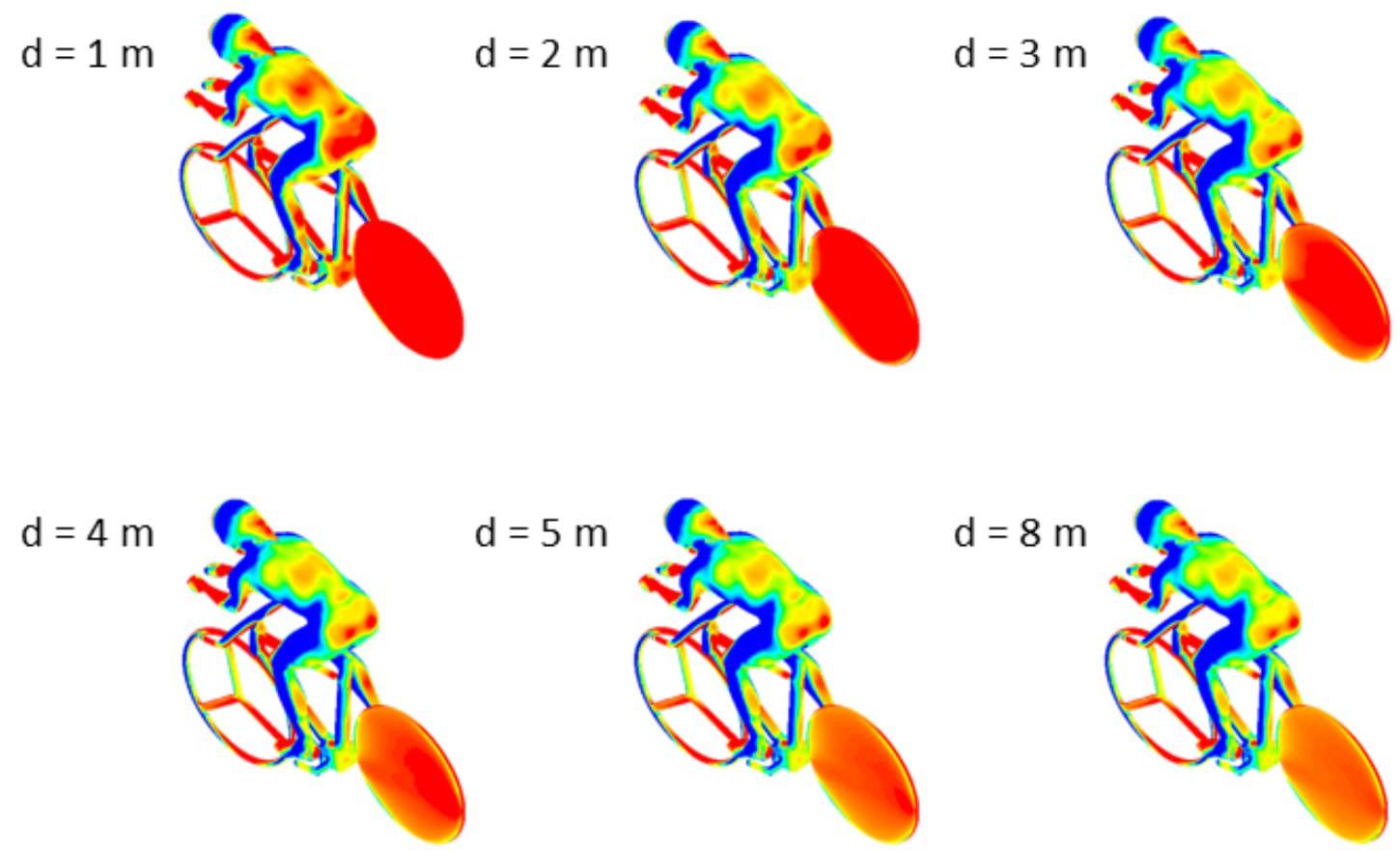

$\mathrm{d}=8 \mathrm{~m}$
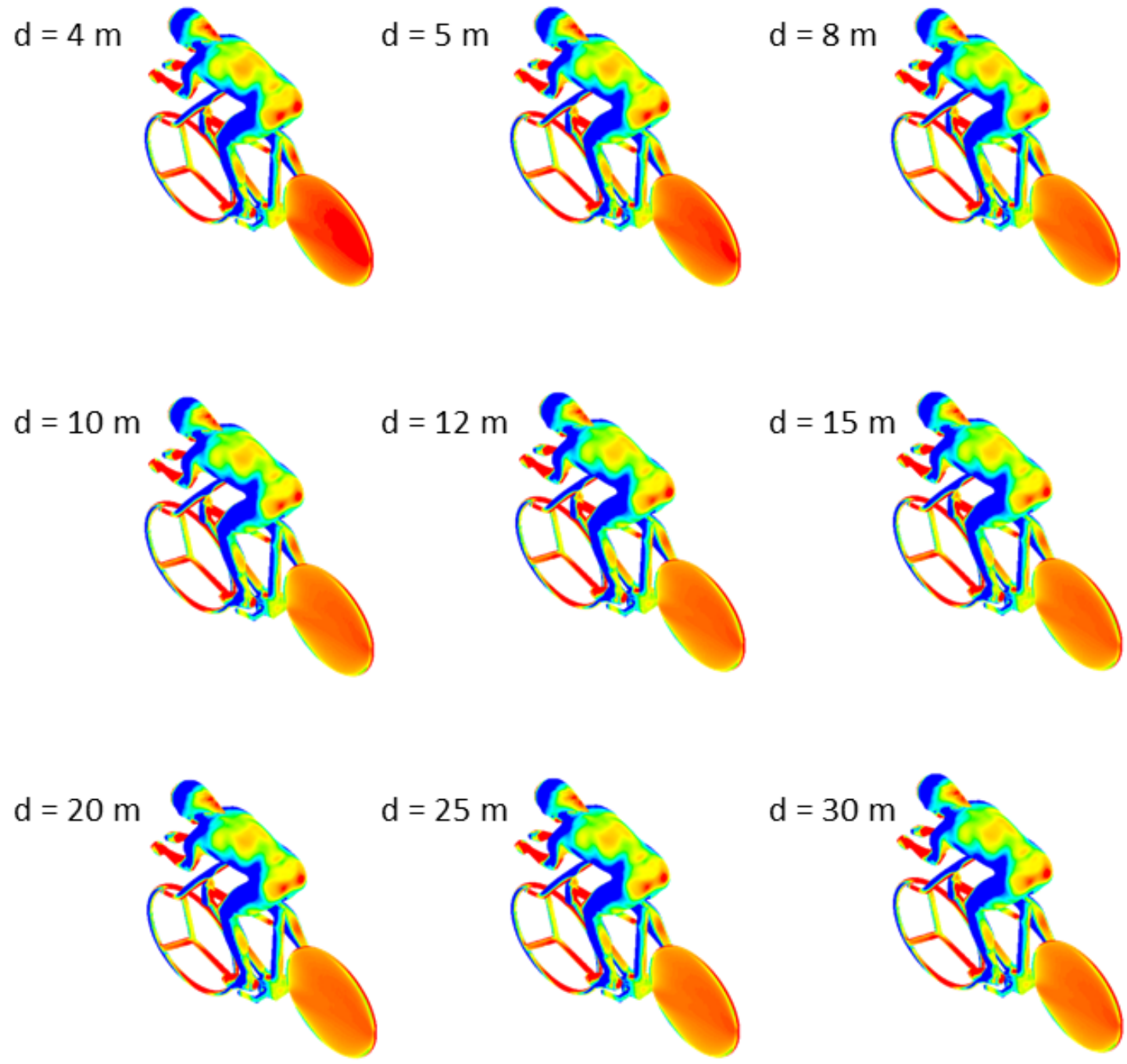

\section{Pressure Coefficient $\left(C_{p}\right)$}

$\begin{array}{lllllllllll}<-0.5 & -0.45 & -0.4 & -0.35 & -0.30 & -0.25 & -0.2 & -0.15 & -0.10 & -0.05 & >0.00\end{array}$

Figure 9. Pressure coefficients $\mathrm{C}_{\mathrm{P}}$ on the body of the cyclist and bicycle followed by car for separation distances from $\mathrm{d}=1 \mathrm{~m}$ up to $30 \mathrm{~m}$, at cycling speed of $15 \mathrm{~m} / \mathrm{s}(=54 \mathrm{~km} / \mathrm{h})$. 


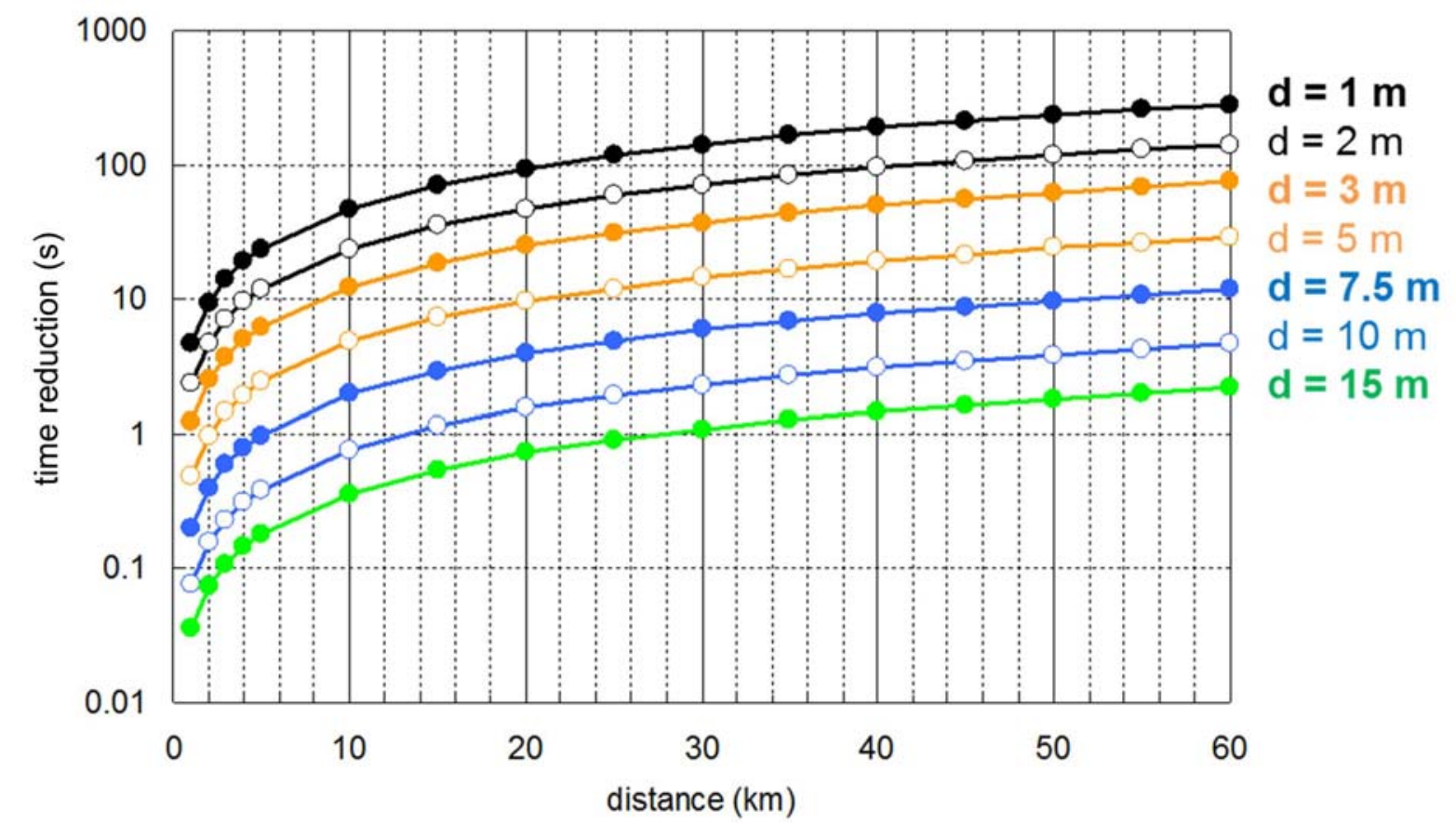

Figure 10. Nomogram indicating potential time reduction in an individual time trial as a function of the time trial distance, with the separation distance between cyclist and car as a parameter.

Table 1. Drag reduction (DR) in percent as a function of separation distance d between cyclist and car.

\begin{tabular}{|c|c|c|c|c|c|c|c|c|c|c|c|c|}
\hline $\mathrm{d}(\mathrm{m})$ & 1 & 2 & 3 & 4 & 5 & 8 & 10 & 12 & 15 & 20 & 25 & 30 \\
\hline $\mathrm{DR}(\%)$ & 13.67 & 7.03 & 3.71 & 2.10 & 1.44 & 0.45 & 0.23 & 0.18 & 0.11 & 0.03 & 0.02 & 0.02 \\
\hline
\end{tabular}

